\title{
Genocídio e resgate dos "Botocudo"
}

\author{
ENTREVISTA COM AILTON KRENAK
}

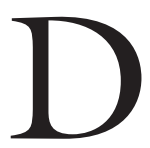
URANTE trezentos anos, a região leste do Estado de Minas Gerais não podia ser devassada. A Coroa portuguesa impedia a passagem direta da região das minas até o litoral, para evitar o contrabando de ouro e diamantes. Criou-se, assim, o chamado "sertão do leste". Com o esgotamento das minas, no fim do século XVIII, tornou-se indispensável derrubar e explorar a Mata Atlântica e exterminar os chamados índios "botocudos", que enfrentavam os colonizadores. Houve, portanto, o genocídio dos índios. Atualmente, as comunidades indígenas estão renascendo e se fortalecendo, exigem respeito pela sua identidade étnica e o atendimento de suas necessidades.

A entrevista com Ailton Krenak, líder da comunidade Krenak e assessor para assuntos indígenas do governador Aécio Neves, foi concedida em setembro de 2008, em Belo Horizonte (MG), ao jornalista Marco Antônio Tavares Coelho, editor-executivo da revista ESTUDOS AVANÇADOS, e também será publicada no livro Rio Doce - Contrastes e confrontos.

Marco Antônio Tavares Coelbo - Inicialmente, peço a você dados sobre sua vida, formação escolar, onde vive e o que faz como porta-voz mais autorizado da comunidade krenak em Minas Gerais.

Ailton Krenak - Nasci em 1953, pois, do final de 1920 até a década de 1940, todas as famílias indígenas foram assentadas por Rondon na reserva do Posto Indígena Guido Marlière, que fica nos municípios de Resplendor e Conselheiro Pena, na margem esquerda do Rio Doce. Nasci do outro lado do rio, porque naquela época essa área começou a ser ocupada pelos criadores de gado. Eles enxotaram os índios dali, que fugiram para o Pankas, no Espírito Santo. Outros foram para o lado do Kuparak.

Naquele lugar houve um massacre causado pelos colonos. Incendiaram a aldeia, fuzilaram crianças e as mulheres e mataram muitos a facão. Isso ocorreu no final dos anos 1940 e 1950 e não havia ali nenhuma família instalada pacificamente.

Até 1970, toda a minha gente permaneceu naquele lugar algum tempo - uns por três meses, por um ano e meio - quando da refrega com os colonos. Acabaram todos expulsos. As últimas famílias que persistiam em permanecer foram arrancadas de lá, amarradas em correntes em cima de caminhões e despejadas em outro sítio, que a Secretaria da Agricultura de Minas Gerais trocou 
com a Fundação Nacional do Índio (Funai) a fim de liberar terra indígena para a colonização.

Despejaram os índios em propriedades da Corregedoria da Polícia, numa Colônia Penal, ou coisa assim. A perspectiva era aniquilar mesmo com o resto das famílias dos índios. Nesse lugar chamado Fazenda Guarani, em Carmésia, foram despejadas algumas famílias. Outras foram para Goiás, porque tinham parentesco com pessoas que viviam na Ilha do Bananal e nunca voltaram. Andei junto com meu pai e com alguns tios e fomos para o interior de São Paulo.

Sou um autodidata. Frequentei uma escola pública em São Paulo, de primeiro grau. Fiz um curso de artes gráficas no Senai, quando tinha dezenove anos. Esse aprendizado é que me deu habilitação para fazer todas as coisas que consegui fazer, inclusive obter de volta as terras que os colonos tomaram de minha família. Hoje é uma aldeia Krenak - o Posto Indígena Guido Marlière. O Estado de Minas respeita os limites dessa terra, pois é da União e o usufruto é dos Krenak.

\section{Um jacobino ao lado dos índios}

M. A. T. C. - Quando e como você começou a estudar a luta e a resistência dos "Botocudo" contra os colonizadores luso-brasileiros?

$A$. $K$. - Nos últimos vinte anos, conheci alguns dados que estavam escondidos sobre os "Botocudo", pois só eram publicados documentos do Arquivo Público Mineiro, apenas informando sobre as campanhas militares contra a minha gente. Depois disso, recentemente, passei a conhecer materiais que estavam fora do Brasil - na França e Portugal. Também tive a oportunidade de visitar um acervo sobre os "Botocudo" num museu em São Petersburgo, na Rússia. Foi um acaso, porque fui atrás de restos da cultura material de meu povo. Esses dados estão em meu texto "O baú do russo", uma historinha curtinha, onde relato a aventura dessa expedição científica. ${ }^{1}$

Nela, há cem anos, no meio de um acampamento "Botocudo", baixaram alguns homens, remanescentes das campanhas do francês Guido Thomaz Marlière, um jacobino que defendeu minha gente. Marlière teve contato com aqueles guerreiros que conseguiam se articular, fechar os caminhos e dar uma surra nos brancos, desmantelados e sem coesão.

Nessa ocasião, os “Botocudo” estavam desbaratados, jogados nos pés-deserra. Muitos foram para o vale do Rio São Francisco, outros foram para o Rio São Mateus, e outros se refugiaram para o lado do vale do Rio Mucuri. Havia poucos assentamentos, pois os "Botocudo" dominavam poucos lugares. Ficavam escondidos, parecendo uma manada de gente assustada.

Quando entrou em contato com os "botocudos", Marlière tentou rearticular um pedaço de gente dizimada, tentando concertar uma política lançada com a declaração de guerra de extermínio, assinada pelo príncipe regente, em 1808. Essa caçada brutal aos "Botocudo" durou duas décadas. Nesse período, chamava-se de "Botocudo" todo ajuntamento de índios, principalmente os apanhados nas matas do Rio Doce, ou até o Espírito Santo. 
Muitas pessoas, quando se referem a "Botocudo", pensam nessa gente do Rio Doce e, no máximo, no massacre da cidade de Conceição do Mato Dentro. Os "Botocudo" não eram ribeirinhos, mas gente do sertão. Gostavam de ficar na beira dos rios porque os rios eram uma fonte de alimentação, além de uma orientação de rota. Na sua natural sabedoria, buscavam lugares saudáveis e com água limpa. Só quando a mata começou a ser infestada de brancos apareceram a malária e outras doenças. Então, os "Botocudo" ficaram com medo de beira de rio.

Essa é a lição contada por nossas avós, como ensina a memória de gente que tinha contato com os brancos. As mais velhas que nossas avós viveram duzentos anos atrás. Elas, quando contavam um caso, partiam do que era contado pelas avós delas.

\section{A. T. C. - Não havia doença no período anterior?}

A. K. - Os "Botocudo" só começaram a sofrer com as epidemias quando os brancos entraram na mata. Depois do contato com os brancos é que apareceram as doenças, a mortandade de crianças e moléstias na pele. Males levados pelos brancos para famílias de índios. A ponto de os índios de um córrego não socorrerem índios de outros córregos em contato com brancos. Eles até evitavam receber esses índios nos acampamentos porque podiam trazer doenças. Os mais sabidos davam um jeito de ficar sempre pelados, porque tinham medo das roupas usadas pelos brancos.

Estou contando essas memórias, desorganizadas no tempo, pois algumas são lembranças contadas em minha casa. Outras são coisas publicadas em trabalhos de pesquisadores, ou aprendidas em discussões em torno de questões fundiárias ou políticas, nas quais foram surgindo documentos para elucidar alguns casos.

É o ocorrido, por exemplo, quando foi discutido o direito dos "Botocudo" sobreviventes de conflitos sobre a terra, em relação a territórios no médio Rio Doce. Isso porque houve pesquisas em documentos de diferentes fontes para analisar dados do impacto ambiental da hidrelétrica construída em Aimorés, quando foram contratadas consultorias especializadas para fazer o relatório do impacto ambiental.

Por isso, conseguimos uma bibliografia extensa sobre diferentes períodos, de 1700 até 1800, esclarecendo acontecimentos envolvendo a administração, o surgimento de vilas e de fazendas, inclusive os primeiros empreendimentos de modelos capitalistas consolidados mostrando como esse negócio foi mudando.

M. A. T. C. - Como posso conseguir esse material?

A. K. - Vou juntar o material todo. Relatórios sobre a hidrelétrica de Aimorés, um relatório etnoambiental ${ }^{2}$ que vem desde o Von Martius até o príncipe Maximiliano. Esse publicou um vocabulário de palavras usadas pelos "Botocudo". ${ }^{3}$ Uma fonte interessante é um caderno de Teófilo Otoni, falando sobre a floresta, o rio e os "Botocudo" no Rio Doce. A Universidade Federal de Minas 
Gerais publicou um livrinho muito inteligente em que Teófilo Otoni relata o empreendimento do Projeto Mucuri e a briga dele com os índios. ${ }^{4}$

\section{A atuação de Teófilo Otoni}

M. A. T. C. - Em geral, Teófilo Otoni teve uma relação boa com os índios?

$A$. K. - Na época, não podia fazer outra coisa. Foi mais ou menos como o Orlando Villas Bôas, pois esse também agiu como humanista no caso do Parque Nacional do Xingu. Se Teófilo Otoni tivesse sido ouvido e respeitado os "Botocudo", esses não teriam sido aniquilados. Além disso, ele tinha também a ambição de encontrar, no meio dos "Botocudo", uma gente chamada de aimoré - os tais índios Aimoré.

\section{A. T. C. - Essa expressão aimoré é errada? Não havia esse povo?}

$A$. K. - O Teófilo Otoni era um cara inteligente e honesto. Depois de ter brigado com os "Botocudo", continuava procurando os aimorés, porque acreditava que eram uma tribo muito valente e tinham um tipo de herança cultural diferente da dos "Botocudo". Acreditava serem um ramo na história dos "botocudos". Ora, aimoré é embaré, gente do mato, amba de gente.

\section{A. T. C. - Então, os aimorés não eram uma etnia?}

$A$. K. - Não, eles eram chamados de aimorés pelos Tupi do litoral, muito sabidos. Eles chamavam todos índios do mato de embaré, porque usavam esse nome no sentido de serem brutos. Eram jagunços dos brancos e chamavam as outras tribos de gente do mato. Assim, esse nome "aimoré" não nomeia um povo, era um apelido dados pelos Tupi. Teófilo Otoni procurou esses aimorés no meio dos "Botocudo". Não achou, mas encontrou fragmentos deles, rastros deles.

Então, há uns chamados, por exemplo, Naknanuk. Nak é terra; até hoje no dialeto burum (índio na língua dos Krenak). Kren é cabeça. Então, somos os cabeças da terra. Esse grupo nosso é remanescente dos cabeças da terra. Mas há também os outros, uns refugiados que foram sobrando no meio de nossas famílias. São, por exemplo, chamados de Nakrehé, e tem os outros Pojitxá e os Gutkrak.

Quando você vai observar esses nomes, entende uma coisa: tudo é nome de lugar. Seria equivalente chamar o pessoal da serra de serrano; o pessoal da beira do rio de ribeirinho; o pessoal de pântano de pantaneiro; e o pessoal da grota de groteiro. Naquele contexto, chamavam todos de "Botocudo".

Estive lendo o livrinho do Teófilo Otoni e vi como ele mostrou ser inteligente ao observar todo mundo falando desses aimorés, mas ninguém descreveu esses aimorés. Mas sobre os "Botocudo" há diversas referências e ordens sobre os quartéis espalhados, entre Espírito Santo e Minas. Informações sobre centenas deles presos, vigiados e impedidos de sair dos quartéis. Isso ocorreu no final do século XVIII, quando os administradores estavam apavorados e por isso pediram uma ordem de guerra contra os "Botocudo". 
Além disso, esse fato coincide com a liberação do caminho das minas. É insistente essa informação de historiadores escrevendo sobre a liberação da passagem pela floresta do Rio Doce depois de haver se esgotado a extração de diamantes e ouro.

Só depois de liberaram a mata, viram como ela estava cheia de tribos. Até o final do século XVIII, os "Botocudo" ficaram à vontade na mata do Rio Doce. Durante uns cento e tantos anos ficaram ali e a Coroa não tinha nada a ver com aquilo. Depois os brancos decidiram descer o cacete. Antes somente se interessavam pela madeira existente na mata.

\section{Rondon e os krenaks}

M. A. T. C. - Como foi a sobrevinência dos indios depois da guerra decretada pelo principe regente, em 1808; e posteriormente, como foi o relacionamento dos brancos com os indios? Atualmente, como é esse relacionamento?

A. K. - Quero colocar uma questão-chave. Há muitas informações sobre o massacre ocorrido na guerra ofensiva. Mas não tenho clareza como terminou a guerra. A partir da pregação de Guido Marlière e de Teófilo Otoni, como os "Botocudo" se juntaram? A tradição oral, que chegou até a minha geração, diz que a guerra nunca cessou. Só diminuiu porque um dos lados não tinha mais contingente para combater. Mas os "Botocudo" continuaram sendo sangrados como galinhas, ao longo de todo o século XX.

Darcy Ribeiro apresentou esses índios como extintos. Uma vez, quando ele era secretário de Cultura, do governo Brizola, fui visitá-lo com um grupo de guaranis no Rio de Janeiro. Por coincidência, nesse dia havia caído um temporal. Fomos andando a pé, da rodoviária até a Secretaria. Parecíamos uns pintos molhados. O guarda da Secretaria estranhou e disse que o secretário não iria receber aqueles pedintes descalços, com calças e camisas molhadas. Mas, apesar disso, entramos no gabinete do Darcy para cumprimentá-lo e ele perguntou como é que estávamos. Respondi: "Como você disse que nosso povo está extinto, um fantasma veio the visitar. Porque, pelo seu livro, estamos mortos. Quem está extinto não dá notícia”.

Darcy deu uma risada e perguntou: "Continua a matança em cima de vocês?". Falei: "Claro que continua. Vim aqui pedir sua intervenção junto ao governo para que a Funai e as outras agências do governo parem essa perseguição contra as restantes famílias de 'Botocudo"'.

O que aconteceu foi o seguinte: quando acabou a guerra, se é que houve o final dessa guerra, uma missão de capuchinhos estava tentando consolidar um assentamento onde viviam mais de 2.700 "Botocudo". Uns cacos de gente, no final do século XIX, lá num vilarejo em Itambacuri, no vale do Mucuri. Em 1893, houve uma rebelião. Os índios mataram os que chefiavam a missão dos capuchinhos e saquearam propriedades e sítios. De 1893 até 1910, 1915, havia muito ressentimento e ninguém queria ver aqueles índios que fugiram da missão, quase mansos, e que de novo viraram bravos. O problema é que nessa 
segunda rebelião os índios não estavam mais com arco e flecha, mas com carabina. Começaram a assaltar as tropas com rifle e munição. Tomaram as armas dos tropeiros e formaram uma jagunçagem. No meio dessa jagunçagem surgiu um capitão, um sujeito guerreiro, o capitão Krenak.

Esses guerreiros deram muito trabalho na ocupação do Rio Doce, naquele lugar, que hoje tem o nome de Nanuk, palavra na língua dos "Botocudo". Nome de um cara rebelde, que comandava uma horda de bravos guerreiros, cercando as tropas. Seguiam pela rota de tropeiros que havia na região, tomando suprimentos de qualquer provedor. Alimentavam os grupos de seus guerreiros na Serra dos Aimorés.

Foi aí que o marechal Rondon, com o Serviço de Proteção aos Índios (SPI), mandou seus bons indianistas/sertanistas, que saíam do Rio de Janeiro, de Cuiabá e de outras regiões, para pacificar os "Botocudo". Assim foram pacificados esses últimos guerreiros. Desses sertanistas, alguns eram oficiais. Eles atribuíram a patente de capitão a esse Krenak. Somos descendentes da família dele. Trocou o botoque dele, com um fotógrafo, por comida. Roquete Pinto fez uma foto dele quando ele já estava tuberculoso. Em troca de sua foto, ganhou os brincos e os anéis da orelha, que foram levados para o museu.

Desse período de 1910-1925, são pequenas narrativas que contam os momentos de visita de autoridades, os momentos de namoro e depois os momentos de matar todo mundo. Até que, em 1922, por orientação do marechal Rondon e da turma dele que havia criado o SPI, houve a localização desses índios.

Rondon deu um jeito para arrumar um lugar para aqueles índios, demarcando uma reserva, um território para eles, e liberava o entorno dos assentamentos. Chamava trabalhadores nacionais e organizava uma colonização. Rondon dirigia, ao mesmo tempo, o Serviço de Proteção dos Índios e também a localização de trabalhadores.

\section{O massacre permanente dos "botocudos"}

\section{A. T. C. - Como você vê esse problema do relacionamento hoje?}

A. K. - Acompanhando a história do Brasil até a Constituinte de 1988, não só em Minas, mas no Brasil inteiro, a perspectiva do Estado brasileiro era acabar com índio. Só que na Constituinte houve uma grande pressão para mudar essa política.

Esse negócio de a literatura dizer que os "Botocudo" eram antropófagos é um ato falho, é um truque da má consciência neobrasileira formadora do Brasil. Eles tinham de dizer que minha gente era antropófaga para nos aniquilarem. Participei na Constituinte de 1988 pintando a cara de preto no Congresso Nacional. Estava com 36 anos de idade quando fiz aquilo. Fui defender a emenda popular, pois não se defendia o artigo 231 da Constituição porque ele afirma que o Brasil precisa parar de matar índio e assegurar os direitos para os índios restantes.

Isso tudo foi uma ruptura com o que havia acontecido no passado. $\mathrm{Mu}-$ 
dança que o Estado não conseguiu assimilar até hoje, pois o Estado ainda tem cacoetes. O Estado parece uma daquelas feras que ficam mansas, mas, de vez em quando, ainda comem alguém. Ainda agora há os pit bulls soltos lá em Roraima. Eles se esquecem de que há uma Constituição. Mas o ministro do Supremo Tribunal Federal lembrou muito bem em seu voto, dizendo: "Tirem os dentes, tirem as presas". ${ }^{5} \mathrm{O}$ que aconteceu da Constituinte para cá foi um fenômeno fantástico, o surgimento de nova identidade.

No século XX, em Minas Gerais, se dizia que não havia mais índios, ou que no máximo havia "Botocudo" sobreviventes e Maxacali (aqueles de Mucuri, de Santa Helena e Bertópolis). Esses Maxacali são um fenômeno impressionante, pois não se aculturaram. Você chega numa aldeia maxacali e eles estão falando a língua deles, vivendo na religião deles, vivendo no mundo deles. Pelo menos nos últimos duzentos anos ficaram isolados. Tempos atrás estiveram em Diamantina e em outras regiões, no Jequitinhonha. Mas, nos últimos duzentos anos, fizeram um movimento e se fixaram nessa região do Mucuri. Eram inimigos preferenciais dos "Botocudo". Quando não havia branco para brigar, os "Botocudo" brigavam com os Maxacali. O que resultava em roubo de mulheres de um lado e do outro. Logo, nós somos parentes, somos parentes porque nossos grupos guerreavam e tomavam crianças uns dos outros, e mulheres uns dos outros.

\section{A. T. C. - Quantos são os indios em Minas Gerais?}

A. K. - Os maxacalis eram considerados as últimas famílias indígenas sobreviventes em Minas Gerais, quando, por volta de 1970/1980, houve o ressurgimento dos Xacriabá que estavam submersos na história e começaram a reivindicar terra, direitos e identidades. Hoje é a população indígena mais numerosa do Estado de Minas. São mais ou menos oito mil índios, enquanto os Krenak são duzentos e poucos. Numericamente nós não existíamos e eles existiam. Mas até o século XX não existiam.

Hoje os Maxacali são uns 1.200 ou 1.300. Se juntar esses povos, que ficaram nesse lugar demarcado, atravessaram o século XX, eles são os Krenak, Maxacali e Xacriabá. Hoje, quando se olha o site da Secretaria de Governo encontramse nove tribos em Minas. Que fenômeno é esse? Os Patachó, que fugiram lá da Bahia, perseguidos pela turma do Antônio Carlos Magalhães, se refugiaram em Minas, na década de 1960/1970. Os índios parentes de Graciliano Ramos, de Palmeiras dos Índios, Xukuru-Kariri, fugiam da miséria, do desmando político, da violência, e vieram para o sul de Minas, que os recebeu. Aqui há três grupos de famílias indígenas: Pataxó, Xukuru-Kariri e Pacararu.

Foi tão bom esse período de ressurgimento das comunidades indígenas que, quando o governador Aécio Neves me chamou, em 2003, e me perguntou como estavam os índios em Minas Gerais, respondi: "Estão muito mal".

\section{$\mathrm{O}$ que fazer pelas comunidades indígenas?}

M. A. T. C. - O que vocês têm feito pelos indios? Qual o resultado desse trabalho? 
A. K. - O que dá resultado é tratar esse conjunto de famílias tribais, remanescentes desses povos - Xacriabá, Maxacali e inclusive dos que migraram para cá vindos do Nordeste, Pataxó, Xukuru-Kariri, Pacararu, além dos nativos Aranã e Kaxixó - como cidadãos que têm direito à proteção do Estado, sem discriminação. Eles têm direito às políticas públicas no sentido de atendimento às mães, quanto ao nascimento de seus filhinhos, o pré-natal e o acompanhamento dessas mães até que a criança faça cinco anos de idade. Têm direito à alimentação. Deve-se respeitar o direito dos índios de continuar morando em casa de palha que fizeram, dando a eles e elas a oportunidade de, se quiserem, ter uma habitação adequada. Porque não admito que arranquem um costume, que é próprio de uma família indígena, para botá-la num conjuntinho residencial do Banco Nacional de Habitação (BNH).

A gente não tem povo indígena vivendo num apartamento do $\mathrm{BNH}, \mathrm{em}$ Minas Gerais, pois temos nos esforçado para arrecadar terras públicas, seja terra da União seja terra do Estado, para criar assentamentos adequados para atender às necessidades dessas famílias indígenas. Uma família indígena reduzida a 200 ou 300 indivíduos não quer viver nos fundos de uma fazenda, hostilizada por pecuaristas ou por garimpeiros. Ela sente a necessidade de estar num lugar mais parecido com essas unidades de conservação, num parque ou numa unidade biológica.

Estamos argumentando no sentido de que os índios possam ter acesso a um lugar desse tipo e que o Estado crie os instrumentos para que eles possam viver desse modo, não agredidos pelo município ou pelos vizinhos. Isso deve ser feito através das secretarias de Estado, como as da Saúde, do Meio Ambiente, de Agricultura ou de Bem-Estar Social. Programas públicos para realizarem ações que atendam a questões como água potável, para eles pararem de beber água de córrego que está envenenada com agrotóxico, com esgoto, com detritos de todo tipo.

A água do Rio Doce está muito ruim. No meio dela há partículas de mercúrio, bauxita e outros minérios pesados, fora os resíduos jogados no Rio Doce pelos municípios, desde o Rio Piracicaba. Quando a gente toma banho, sai bronzeado, mineralizado. Num seminário no médio Rio Doce acusei os municípios de serem responsáveis por jogarem detritos no rio. Uma pessoa se levantou e disse: "Em Ipatinga não se faz mais isso, pois tratamos de nossa água, antes de jogá-la no Rio Doce". Ora, mas, em Governador Valadares, jogam restos de hospital, sofás velhos, televisões e até geladeiras dentro do rio. Todo mundo na beira do Watu (nome que os índios dão ao Rio Doce) acha que ele é o depósito de todos seus restos.

\section{O ensino em língua indígena}

M. A. T. C. - Na educação primária as professoras ensinam a língua materna das comunidades indígenas?

A. K. - Temos um programa chamado Piei (Programa Estadual de Im- 
plantação das Escolas Indígenas). O Estado de Minas tem hoje duas mil crianças indígenas em sala de aula, com professor bilíngue da aldeia. Todas a aldeias têm uma escola indígena bilíngue, com professor nativo local, que foi habilitado pela Universidade Federal de Minas Gerais (UFMG), em oito módulos de quatro anos, para se tornar um professor habilitado em magistério.

Desses professores, 140 deles estão fazendo licenciatura na Universidade e vão se graduar em 2010 como educadores em língua e literatura. Nossa população é de nove etnias diferentes. Dessas etnias, só três mantêm a língua materna. Mas mesmo aquelas que não têm a língua materna estão tendo subsídio e material didático de apoio a fim de trabalharem a reintrodução da língua materna. Estamos gerando esses materiais com apoio não só em programas estaduais, mas também em programas federais, porque o Ministério da Educação tem um comitê de educação indígena que foi implantado no governo de Fernando Henrique. Esse comitê tem se constituído num espaço bem democrático de pluralidade.

O material didático é impresso em português e na língua materna, caso o grupo tenha memória da língua materna, porque não tem sentido mandar um texto escrito em língua tupi do tempo de Anchieta para uns remanescentes de índios tupis, mas que não conhecem mais essa língua.

\section{A tradição e a religião dos índios}

M. A. T. C. - Ainda há pressão da Igreja Católica para as comunidades indígenas aderirem à religião católica? Como você encara o problema da religião?

A. K. - A disputa religiosa atualmente foi incrementada pela chegada dos evangélicos. Antes, os missionários queriam só as almas dos índios, agora eles disputam com os evangélicos a governança dos índios. Se você catequiza o índio e o deixa seguir a vida dele, tudo bem. Mas se catequizá-lo e ficar mandando, fazendo a governança de suas vidas, organizando em comunidades, sindicatos, associações e coisa que o valha, isso eu acho grave.

A disputa dos índios por católicos e evangélicos cria um agravamento da crise de identidade desses índios. Essas disputas são esvaziadoras do conteúdo cultural que os índios herdaram. Estou falando da Pastoral da Igreja Católica, mas os evangélicos também estão fazendo a mesma coisa. Querem ficar pau a pau com os católicos para ver quem controla o índio.

M. A. T. C. - Quer dizer que não há uma abertura da Pastoral desse ponto de vista de religião?

A. K. - Com aquelas mudanças do concílio dos anos 1960/1970, aquelas coisas de Leonardo Boff, da Teologia da Libertação, dizem que estão espalhando cultura ecumênica. Os missionários da Teologia da Libertação falam com os índios que estão encarnando a cultura indígena. Você pode encontrar um missionário dançando com o pajé, mas esse negócio do missionário dançar junto com o pajé é só conversa. Porque na verdade, quem prega, quem instala o bastão lá dentro, prega a cruz, marca a hora do catecismo, é o missionário, não é o pajé. 
O que observo nessa virada do século XX para cá é que o fenômeno da globalização, junto com essas outras manifestações locais, como a disputa com os evangélicos, estão jogando os índios num liquidificador, indiferentemente se são índios tradicionais ou índios aculturados. Eles querem tirar daí médicos, técnicos, vereadores, políticos, administradores, educadores, professores.

$\mathrm{Na}$ verdade, costumo dizer o seguinte: dois séculos de guerra bruta não conseguiram fazer o serviço que um pequeno período de democracia está fazendo - o de integrar de maneira absoluta essa diversidade cultural.

Índios são uma generalização absurda, porque acaba com isso que nós estamos falando que é a possibilidade do menino na aldeia ensinar a seus irmãos, do avô ensinar a seus netos a sua história, ensinar na sua língua seus valores e a sua tradição.

Esvaziam tudo isso e enfiam lá um monte de representação e dizem: "Essa é do comitê de não sei o quê", "o conselho de mulher", "o de saúde", "de educação". Eles vão esvaziando a identidade desse índio e ele acaba virando uma espécie de uma figura parecida com sindicalista.

Essa novidade de todo mundo virar cidadão (de forma compulsória) tira também das pessoas a possibilidade de elas continuarem vivendo de alguma maneira a memória de sua tradição, de sua cultura. Daqui a pouco eles vão perder a possibilidade de ter um terreiro dentro da aldeia onde as pessoas ficam sentadas, calam a boca e escutam os velhos. E quando um velho vier e falar assim: "Esse mês nós vamos nos recolher numa ilha do Watu e vamos fazer os ritos de passagem dos que têm menos de onze anos de idade. Eles vão ficar afastados do convívio de suas mães e de suas famílias e vão ser iniciados na história dos velhos que não podem ser contadas publicamente. Quando não puder fazer mais isso não irá fazer diferença nenhuma ter língua diferente. Papagaio repete também língua diferente!”.

A importância de ser bilíngue e de ter liberdade para pensar é continuar uma narrativa, seja recebida no sonho, nos ritos, nisso que eles chamam de religião. Índio não tem religião. $\mathrm{O}$ mais autêntico que a gente pode identificar num núcleo de uma prática dessas famílias desse povo antigo é a continuação da tradição. Uma tradição que remonta aos mitos da criação do mundo.

Então, assim é muito bom quando os Krenak podem se recolher no taruandé, que é um rito que os Krenak guardaram na memória deles. Taru é o céu, taruandéé um movimento que o céu faz de aproximação com a Terra. No taruandé os meninos que ainda estão engatinhando, os homens, as mulheres, os mais velhos cantam e dançam juntos, como uma brincadeira de roda. Repetindo frases na sua língua materna que diz: "O meu avô é a montanha", "Você é meu avô e o rio", "Você é peixe pra eu comer", "Você me dá remédio para a minha saúde", "Você esclarece minha mente e meu espírito", então "O vento, o fogo, o sol, a lua".

Ficam repetindo essas frases na sua língua ancestral, batendo o pé no chão, 
tocando maracá, acendendo fogo, pulando na água fria, buscando saúde, fazendo a terapia muito especial e afirmando a sua própria identidade diante do mundo avassalado por propaganda, consumo e besteiras de todo lado.

O que eu valorizo é isso. É que ainda possa ter famílias que olham para si mesmas; não sintam vergonha de ser quem são; não têm vergonha de morar em casa de chão batido; não têm vergonha de cozinhar num fogareiro de cupinzeiro, em cima de pedra; não têm vergonha de comer carne moqueada, comer peixe moqueado assado na pedra, comer batata e mandioca tiradas de baixo das cinzas; não têm vergonha de fazer isso. Acham que fazer isso é um jeito de continuar sendo "Botocudo".

Ora, os árabes, os judeus, os japoneses também batem tambor, comem de palitinho. É um jeito de eles continuarem sendo árabes, judeus, japoneses. Por que a gente não pode continuar sendo "Botocudo" em qualquer lugar? Essas pessoas têm que ter o direito de continuar ensinando para seus filhos os valores que até hoje eles trouxeram vivos consigo.

\section{A luta de um krenak} Gerais?

M. A. T. C. - Qual a sua atuação e sua relação com o governo de Minas

A. K. - O governador Aécio Neves me perguntou: "O que dá pra fazer pelos índios?”. Respondi: "Podemos fazer o que Guido Marlière fazia quando cuidou da questão dos índios, no gabinete militar do Império”. Então, desde 2003, o governador me deu um mandato, de assessor especial para assuntos indígenas. Sou vinculado à Secretaria de Governo. Ele me disse então: "Você vai criar o programa para inclusão social dos que ainda restam de povo indígena no nosso Estado, porque não queremos que sejam aniquilados e desapareçam”.

Assim, de certa maneira, a guerra contra os índios em Minas Gerais só parou com o governador Aécio Neves. O governador me perguntou se teria sentido criar uma Secretaria de Assuntos Indígenas. Respondi que em Minas não há uma população indígena que justifique a criação de uma Secretaria de Estado. Assim, propus fazer meu trabalho no gabinete dele. Disse-me que, então, eu deveria trabalhar em nível de igualdade com qualquer secretário. Empossou-me e avisou aos demais secretários para colaborarem comigo, a fim de cumprir minha missão. O objetivo é trabalhar para que em Minas sejam respeitados os direitos humanos e sociais dos índios.

Tenho, portanto, o compromisso de agir assim até 2010. Nosso propósito é criar um Centro de Referência da Cultura Indígena e um Memorial Indígena, na Serra do Cipó, um sítio que se chamará Monumento Natural da Mãe D’Água. O Instituto Estadual da Floresta, junto com o Instituto Brasileiro do Meio Ambiente e dos Recursos Naturais (Ibama), está demarcando esse sítio. É cheio de grutas, cavernas e sítios arqueológicos da maior relevância. Dentro desse memorial vamos recolher o acervo que foi para a Rússia, a fim de resgatarmos cem anos da cultura material dos “Botocudo". Eles são os primeiros registros 


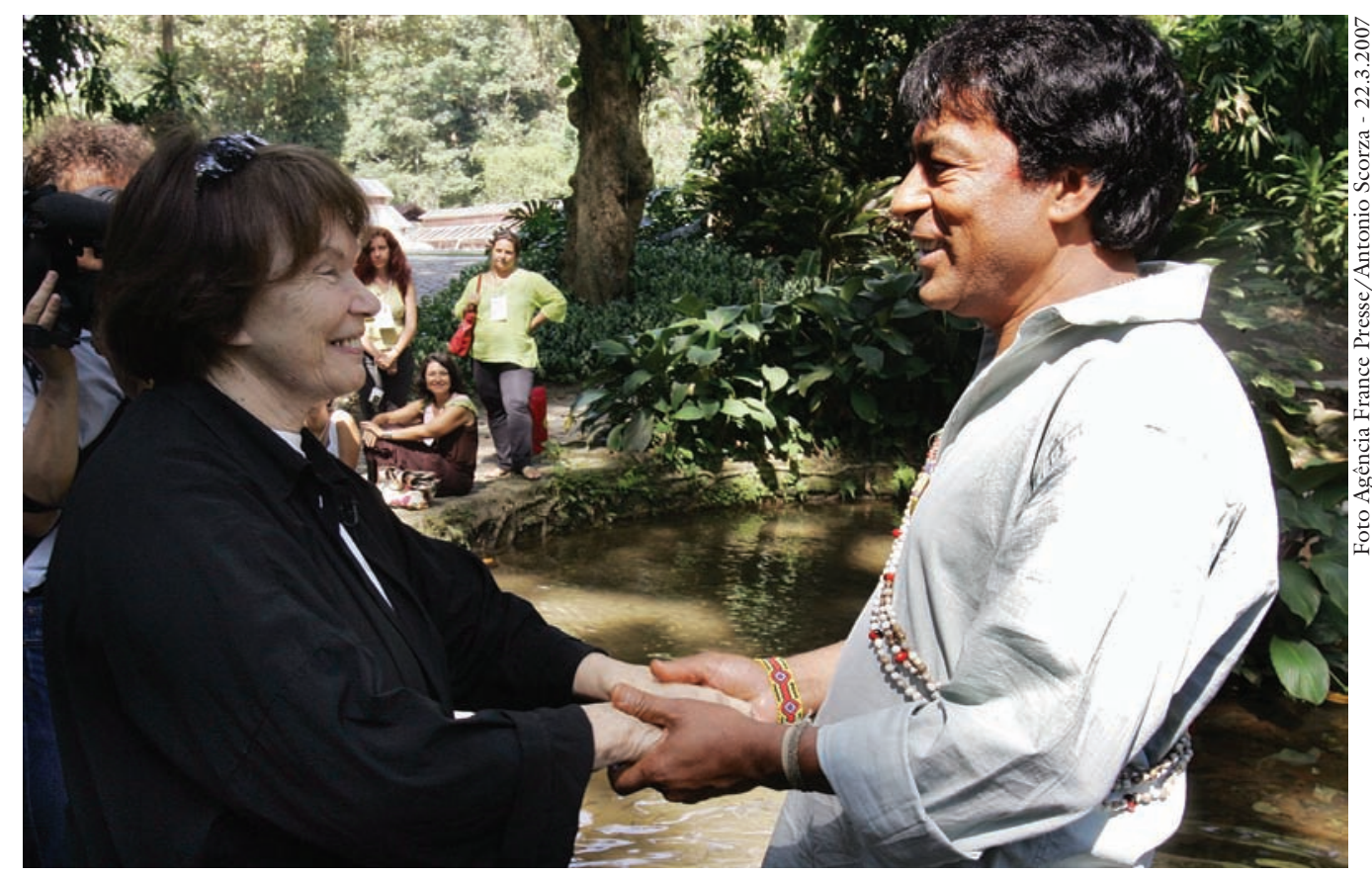

Danielle Mitterrand, representante da Fundação da França para a Liberdade, e o líder indigena Ailton Krenak, durante o Dia Mundial da Água, no Jardim Botânico, no Rio.

das escritas fonéticas de "Botocudo" gravados por essa expedição russa. Em torno desse acervo deveremos ter um espaço para a formação de jovens indígenas, a fim de administrar seus territórios, tendo em vista sua educação e saúde, além de outros objetivos.

Sabe por que escolhi esse lugar? Foi porque é uma das nascentes do Rio Doce, lá em cima da Serra do Espinhaço.

Notas

1 Uma documentação de Manizer, que se encontra no Museu de São Petersburgo.

2 Etnozoneamento ambiental da etnia e terra krenak, elaborado pela Associação Indígena Krenak. Resplendor (MG), 2002.

3 Viagem ao Brasil, do príncipe Maximiliano de Wied-Neuwied (Edusp; Itatiaia, 1989).

4 Livro de Teófilo Otoni, Notícia sobre os selvagens do Mucuri, organização de Regina Horta Duarte (Editora da Universidade Federal de Minas Gerais, 2002).

5 Voto do ministro Carlos Ayres Britto do Supremo Tribunal Federal, como relator no litígio sobre a Reserva Indígena Raposa/Serra do Sol, em Roraima. 